\title{
Determinação de mercúrio total em amostras de água, sedimento e sólidos em suspensão de corpos aquáticos por espectrofotometria de absorção atômica com gerador de vapor a frio*
}

\section{Determination of total mercury in water, sediments and solids in suspension in aquatic systems by cold vapor atomic absorption spectrometry}

José L. F. Vieira e Miriam M. Passarelli

Departamento de Deontologia e Medicina Legal da U niversidade Federal do Pará. Belém, PA - Brasil (J.L.F.V.). Departamento de Análises Clínicas e Toxicológicas da Faculdade de Ciências

Farmacêuticas da Universidade de São Paulo. São Paulo, SP - Brasil (M.M.P.)

\begin{abstract}
Resumo
O emprego de mercúrio metálico nos processos de extração do ouro libera toneladas de mercúrio ao meio ambiente, provocando um aumento considerável nas concentrações presentes. Com a finalidade de prevenir a exposição humana a concentrações excessivas, o que poderá resultar em graves episódios de intoxicação mercurial, bem como avaliar a possibilidade de sedimentos tornaremse fontes potenciais de contaminação para os seres vivos, é de fundamental importância a monitorização do mercúrio em diversos compartimentos ambientais. Efetuou-se a padronização de uma metodologia analítica para determinação de mercúrio total em amostras de água, sólidos em suspensão e sedimentos de corpos aquáticos para monitorização ambiental do xenobiótico. Posteriormente, foram analisadas amostras oriundas de regiões garimpeiras, com vistas a avaliar o desempenho do método em amostras reais e efetuar levantamento preliminar sobre a contaminação mercurial na área de estudo.
\end{abstract}

Mercúrio, análise. Poluentes químicos da água, análise. Expectrofotometria por absorção atômica, utilização.

\begin{abstract}
The use of metallic mercury in the extraction and concentration of gold causes the discarding of tons of this metal in the environment, leading to a considerable increase in the natural levels of the same and the contamination of the surrounding areas. Thus it is extremely important to monitor the presence of this metal in various sectors of the environment with a view aiming to
\end{abstract}

\footnotetext{
* Parte integrante da Dissertação de Mestrado apresentada ao Departamento de Análises Clínicas e Toxicológicas da Faculdade de Ciências Farmacêuticas da Universidade de São Paulo, em 1994. Apresentado no VIII Congresso Brasileiro de Toxicologia, Curitiba, PR, em 1993. Correspondência para/Correspondence to: Miriam M. Passarelli - Departamento de Análises Clínicas e Toxicológicas da Faculdade de Ciências Farmacêuticas da Universidade de São Paulo - Bloco de Apoio ao Ensino e Pesquisa. Av. Lineu Prestes, 580 - 05508-900 São Paulo, SP - Brasil. Edição subvencionada pela FAPESP. Processo 95/2290-6.

Recebido em 11.7.1995. Reapresentado em 13.12.1995. Aprovado em 12.1.1996
} 
previnting human exposure to excessive concentrations which can result in serious episodes of mercury poisoning. It is also important to estimate the possibility of river sediments becoming potential sources of contamination of human beings. The determination of total mercury was undertaken by using cold vapor atomic absorption spectrometry. River waters, as well as sediments and suspended solids were used as samples for the standardization of the analytical procedure. Later on, this method was tested on samples originating in gold mining areas for the purpose of assessing its validity.

Mercury, analysis. Water pollutants, chemical, analysis. Spectrophotometry, atomic absorption, utilization.

\section{INTRODUÇÃO}

O emprego de mercúrio metálico nos processos de concentração e extração de ouro em garimpos acarreta a liberação ao ambiente de toneladas do metal. Dados extra-oficiais mostram que, nos últimos 15 anos, cerca de 1.500 a 3.000 toneladas de mercúrio metálico foram usadas na extração de ouro na Amazônia, onde estão localizadas as principais jazidas do Brasil ${ }^{6,7,11}$.

Acredita-se que, do total empregado, mais de $62 \%$ foi lançado ao ambiente. Isto se deve à ineficiência dos processos de extração do metal nobre, tanto através do despejo direto do mercúrio em corpos aquáticos, quanto pela via da atmosfera. Esta última é resultante da queima do amálgama para recuperação do ouro, com liberação do vapor de mercúrio metálico. Este processo provoca aumento considerável nas concentrações ambientais de mercúrio, fato que poderá levar à exposição humana excessiva, possibilitando a ocorrência de graves episódios de intoxicação mercurial ${ }^{1,4,6,7,8}$.

No meio ambiente o mercúrio sofre uma série de transformações e interações com constituintes dos diversos compartimentos ambientais, tais como: oxidação a íon mercúrico na atmosfera com posterior incorporação a gotículas de água, conversão a derivados alquilmercuriais de cadeia curta, com acúmulo na cadeia alimentar, e deposição em sedimentos, que constituem verdadeiros depósitos do metal, sendo possível tornarem-se fontes potencialmente nocivas de mercúrio $2,4,14,15,16$.

A exposição humana aos compostos de mercúrio presentes no ambiente ocorre pela inalação do vapor de mercúrio ou ingestão de água e alimentos contaminados, principalmente os peixes, os quais concentram alquilmercuriais de cadeia curta ${ }^{5,14,15}$.

O presente trabalho teve como objetivo a padronização de uma metodologia analítica para determi- nação de mercúrio total em amostras de água, sólidos em suspensão e sedimentos de corpos aquáticos para aplicação na monitorização ambiental do xenobiótico, com o intuito de prevenir danos à saúde da população exposta e, também, para avaliar a possibilidade de sedimentos tornarem-se depósitos do metal.

\section{MATERIAL E MÉTODO}

\section{Reagentes*}

Solução padrão TITRISOL ${ }^{\circledR}$ de nitrato de mercúrio; cloreto de metilmercúrio; acetato de mercúrio; cloreto de estanho; permanganato de potássio; ácido sulfúrico concentrado; ácido nítrico concentrado; ácido clorídrico concentrado; etanol $96^{\circ}$ G.L.

No preparo das soluções foi usada água desmineralizada.

\section{Equipamentos e Acessórios}

Espectrofotômetro de absorção atômica, modelo 373, com lâmpada de cátodo oco de mercúrio, Perkin Elmer. Gerador de Hidretos, modelo MHS-10, com célula de quartzo aberta com caminho óptico de $12 \mathrm{~cm}$, Perkin Elmer.

Condições de operação: corrente de lâmpada de cátodo oco de $6 \mathrm{~mA}$; comprimento de onda $253,7 \mathrm{~nm}$; fenda 0,7 $\mathrm{nm}$ (alta) fluxo do gás de arraste $\left(\mathrm{N}_{2}\right) 2,5 \mathrm{ml} / \mathrm{min}$; volume do redutor injetado, $9 \mathrm{ml}$; tempo de registro de absorvância de $40 \mathrm{seg}$.

\section{Vidraria}

Foi empregada vidraria comum de laboratório, após prévio tratamento para descontaminação para metais, que consiste em imersão por um período de $12 \mathrm{~h}$ em banho de ácidos (ácido nítrico concentrado; ácido clorídrico concentrado; água desmineralizada, na proporção de $1: 1: 3$ ); a seguir lavagem abundante com água desmineralizada. 


\section{Amostras}

As amostras de sedimento destinadas a otimização da metodologia analítica foram coletadas na raia olímpica da Universidade de São Paulo. As amostras de água, sedimentos e sólidos em suspensão, coletadas no mesmo ponto, oriundas de regiões garimpeiras, foram coletadas no Estado do Pará, Município de Vizeu.

\section{Metodologia para Determinação de Mercúrio Total em Amostras de Água}

No recipiente de amostras do gerador de hidretos colocar $50 \mathrm{ml}$ de amostra ou de solução padrão de mercúrio inorgânico, adicionar 1,5 ml de solução de ácido nítrico a $30 \%$ (v/v), 2,0 ml de solução de ácido sulfúrico a $30 \%(\mathrm{v} / \mathrm{v})$ e $0,5 \mathrm{ml}$ de solução aquosa de permanganato de potássio a $5 \%(\mathrm{p} / \mathrm{v})$. Agitar vigorosamente, deixar repousar por 3 min e efetuar a quantificação do vapor de mercúrio presente na célula de absorção, após redução do íon mercúrico da amostra com solução de cloreto de estanho a $10 \%(\mathrm{p} / \mathrm{v})$ em solução de ácido sulfúrico a $10 \%(\mathrm{v} / \mathrm{v})$.

Calcular a concentração de mercúrio total das amostras por meio de uma curva de calibração, levando-se em conta o pico de absorvância registrada em período de 40 seg. Analisar as amostras, no mínimo em triplicata, efetuando-se paralelamente um ensaio branco dos reativos com água desmineralizada.

\section{Procedimento Analítico para Determinação de Mercúrio Total em Amostras de Sedimento e Sólidos em Suspensão}

Submeter cerca de $5 \mathrm{~g}$ de sedimento à secagem a $40^{\circ} \mathrm{C}$ por $24 \mathrm{~h}$. A seguir triturar o material, à temperatura ambiente, em gral de porcelana até obtenção de granulado homogêneo, tamisar em tamis de nylon com granulometria de 200 mesh. Dissolver um grama da amostra em $2 \mathrm{ml}$ de água desionizada, transferir a suspensão para balão de fundo redondo conectado a um condensador de refluxo, adicionar $10 \mathrm{ml}$ de ácido nítrico concentrado; colocar em banho de água à temperatura de $60^{\circ} \mathrm{C}$ por $30 \mathrm{~min}$; a seguir adicionar $10 \mathrm{ml}$ de ácido sulfúrico concentrado, tratar durante $30 \mathrm{~min}$ no banho de água a $60^{\circ} \mathrm{C}$; adicionar $10 \mathrm{ml}$ de ácido nítrico concentrado, tratar durante $60 \mathrm{~min}$ em banho de água a $60^{\circ} \mathrm{C}$; adicionar $3 \mathrm{ml}$ de solução aquosa de permanganato de potássio a $5 \%(\mathrm{p} / \mathrm{v})$. A seguir resfriar em banho de gelo, até o término da emanação de vapores nitrosos. Transferir o mineralizado para balão volumétrico de $100 \mathrm{ml}$ e ajustar o volume final da solução com água desmineralizada. Efetuar a determinação de mercúrio total, transferindo $50 \mathrm{ml}$ de amostra para o amostrador do gerador de hidretos; efetuar a redução do íon mercúrico presente com solução de cloreto de estanho a $10 \%(\mathrm{p} / \mathrm{v})$ em solução de ácido sulfúrico a $10 \%$ (v/v); efetuar a leitura da maior absorvância registrada em período de $40 \mathrm{seg}$ e calcular a concentração de mercúrio total por meio de uma curva de calibração; analisar as amostras no mínimo em triplicata. Os resultados são expressos em função do peso seco das amostras. O fluxograma do procedimento analítico encontra-se na Figura.

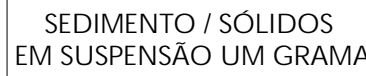

\section{EM SUSPENSAO UM GRAMA}

água desionizada - $2 \mathrm{ml}$

ácido nítrico concentrado $-10 \mathrm{ml}$

banho de água $60^{\circ} \mathrm{C}-30 \mathrm{~min}$

ácido sulfúrico concentrado - $10 \mathrm{ml}$

banho de água $60^{\circ} \mathrm{C}-30 \mathrm{~min}$

ácido nítrico concentrado $-10 \mathrm{ml}$

banho de água $60^{\circ} \mathrm{C}-60 \mathrm{~min}$

permanganato de potássio $5 \%-3 \mathrm{~m}$

resfriar em banho de gelo

cloreto de estanho $10 \%$ em ácido sulfúrico $10 \%$

E.A.A.

Figura - Fluxograma do procedimento analítico para determinação de mercúrio total em amostras de sedimento e sólidos em suspensão.

As amostras de sólidos em suspensão correspondem ao material resultante da filtração das amostras de água em membrana filtrante, com porosidade de $0,45 \mu \mathrm{m}$, Millipore $^{\circledR}$, e são submetidas ao mesmo procedimento empregado para as amostras de sedimento.

Foram efetuados estudos de precisão e recuperação do procedimento analítico proposto, utilizando-se amostras de água e sedimento enriquecidas com concentrações conhecidas de nitrato de mercúrio para avaliação da precisão. Nos estudos de recuperação foram empregadas amostras de sedimento enriquecidas com mercúrio inorgânico (solução aquosa de nitrato de mercúrio) e mercúrio orgânico (solução alcoólica de acetato de mercúrio e solução alcoólica de cloreto de metilmercúrio).

\section{RESULTADOS}

Os resultados da precisão e recuperação do método encontram-se descritos nas Tabelas 1 e 2, respectivamente ${ }^{9}$.

Tabela 1 - Estudo da precisão dos resultados da determinação de mercúrio total em amostras de água e sedimento de corpos aquáticos, em várias concentrações, analisadas por espectrofotometria de absorção atômica com gerador de vapor a frio.

\begin{tabular}{lc}
\hline $\begin{array}{l}\text { Concentração de M ercúrio } \\
\text { total }\end{array}$ & C.V.(\%) \\
\hline $0,1 \mu \mathrm{g} / \mathrm{l}$ de água & $20,0^{*}$ \\
$0,5 \mu \mathrm{g} / \mathrm{l}$ de água & $12,6^{*}$ \\
$1,0 \mu \mathrm{g} / \mathrm{l}$ de água & $6,0^{*}$ \\
$0,1 \mu \mathrm{g} / \mathrm{g}$ de sedimento & $8,2^{* *}$ \\
$0,5 \mu \mathrm{g} / \mathrm{g}$ de sedimento & $6,5^{* *}$ \\
$1,0 \mu \mathrm{g} / \mathrm{g}$ de sedimento & $4,1^{* *}$ \\
\hline
\end{tabular}

* Coeficiente de variação, em percentagem, calculado a partir de 20 determinações de amostras de água.

** Coeficiente de variação, em percentagem, calculado a partir de 10 determinações de amostras de sedimento. 
Tabela 2 - Recuperação de compostos inorgânicos e orgânicos de mercúrio em sedimento, adicionados em diversas concentrações e analisados por espectrofotometria de absorção atômica com gerador de vapor a frio.

\begin{tabular}{lccc}
\hline $\begin{array}{l}\text { Concentração } \\
\text { de } \\
\text { mercúrio }(\mu \mathrm{g} / \mathrm{g})\end{array}$ & $\begin{array}{c}\text { Recupe- } \\
\text { ração* }\end{array}$ & $\begin{array}{l}\text { Recupe- } \\
\text { ração** }\end{array}$ & $\begin{array}{c}\text { Recupe- } \\
\text { ração*** }\end{array}$ \\
\hline 0,1 & 93,4 & 100,3 & 90,7 \\
1,0 & 99,6 & 99,0 & 91,0 \\
5,0 & 89,0 & 99,5 & 82,0 \\
\hline
\end{tabular}

* Recuperação de composto inorgânico de mercúrio, adicionado como nitrato de mercúrio.

** Recuperação de composto orgânico de mercúrio, adicionado como cloreto de metilmercúrio.

***Recuperação de composto orgânico de mercúrio, adicionado como acetato de mercúrio.

O limite de detecção obtido foi de $0,08 \times 10^{-3} \mathrm{mg}$ $\mathrm{Hg} / \mathrm{L}$ e a sensibilidade de $0,10 \times 10^{-3} \mathrm{mg} \mathrm{Hg} / \mathrm{L}$. O método mostrou-se linear em intervalo de concentrações de 0,10 a $50,0 \times 10^{-3} \mathrm{mg} \mathrm{Hg} / \mathrm{L}$, apresentando coeficiente de correlação ( $\mathrm{r}$ ) de 0,996 e equação da reta igual a $\mathrm{Y}=0,027+0,015 \mathrm{X}$.

Os resultados da determinação de mercúrio total em amostras de água, sólidos em suspensão e sedimentos encontram-se descritos na Tabela 3.

\section{DISCUSSÃO E CONCLUSÕES}

Dentre as inúmeras técnicas disponíveis para a quantificação de mercúrio total em amostras de água, sedimentos e sólidos em suspensão, optou-se pela espectrofotometria de absorção atômica com gerador de vapor a frio, que apresentou sensibilidade, precisão, recuperação e faixa de linearidade perfeitamente aplicáveis aos objetivos propostos ${ }^{13}, 14$.

Os resultados da padronização do método demonstram que o mesmo pode ser aplicado à monitorização de águas doces, classes 1, 2, 3 e 4, bem como a efluentes industriais, segundo legislação do Conselho Nacional de Meio Ambiente ${ }^{3}$ (CONAMA), que classifica as águas do Território Nacional, segundo seu uso preponderante em 9 classes. E a água potável, segundo legislação do Ministério da Saúde ${ }^{10}$.

A metodologia deverá ser aplicada com cautela na monitorização de águas classes 5 e 7 , pois próximo ao valor máximo permitido em água salobra, classe 7 , o coeficiente de variação é de $20 \%$; e na água salina, classe 5, deve-se efetuar prévia remoção de cloretos que são interferentes negativos na determinação do metal.

Os estudos de precisão do procedimento analítico, segundo dados da Tabela 1 , demonstram valores de coeficiente de variação, em percentagem, considerados aceitáveis pelas boas práticas laboratoriais. Os estudos de recuperação de compostos inorgânicos (nitrato de mercúrio) demonstraram valores de 89,0\%

Tabela 3 - Resultados da determinação de mercúrio total em amostras de água, sedimentos e sólidos em suspensão oriundos de região garimpeira (Vizeu-Pará).

\begin{tabular}{|c|c|c|c|}
\hline Amostra & $\begin{array}{l}\text { Conc. } \mathrm{Hg} \text { total em } \\
\text { água }(\mu \mathrm{g} / \mathrm{L})\end{array}$ & $\begin{array}{l}\text { Conc. } \mathrm{Hg} \text { total em } \\
\text { sedimento }(\mu \mathrm{g} / \mathrm{g})^{*}\end{array}$ & $\begin{array}{l}\text { Conc. Hg total em sólidos } \\
\text { em suspensão }(\mu \mathrm{g} / \mathrm{g})^{* *}\end{array}$ \\
\hline 1 & 1,14 & 0,096 & 0,056 \\
\hline 2 & 0,48 & 0,010 & 0,080 \\
\hline 3 & 0,59 & 0,085 & 0,020 \\
\hline 4 & 0,63 & 0,080 & 0,290 \\
\hline 5 & 0,80 & 0,250 & ND \\
\hline 6 & 0,73 & 0,047 & 0,056 \\
\hline 7 & 0,32 & $<0,008$ & ND \\
\hline 8 & 0,20 & $<0,008$ & ND \\
\hline 9 & $<0,08$ & 0,061 & $<0,008$ \\
\hline 10 & 0,55 & 0,181 & 0,085 \\
\hline 11 & 0,67 & 0,095 & 0,071 \\
\hline 12 & 0,31 & 0,090 & 0,207 \\
\hline 13 & 1,08 & 0,114 & 0,900 \\
\hline 14 & 0,66 & 3,40 & 0,188 \\
\hline 15 & 0,65 & 0,026 & $<0,008$ \\
\hline 16 & 0,53 & 0,030 & ND \\
\hline 17 & 0,67 & 0,200 & 0,285 \\
\hline 18 & 0,48 & 0,063 & 0,180 \\
\hline 19 & $<0,08$ & 0,061 & $<0,081$ \\
\hline 20 & $<0,08$ & 0,038 & $<0,008$ \\
\hline
\end{tabular}

* Valores expressos em termos de peso seco de sedimento

** Valores expressos em termos de peso seco de sólidos em suspensão

ND - não determinado por insuficiência de material em suspensão 
a 93,4\% e para compostos orgânicos (cloreto de metilmercúrio e acetato de mercúrio), valores de $82,0 \%$ a $100,3 \%$, conforme dados da Tabela 2 .

Das amostras de sedimento analisadas, conforme dados da Tabela 3 , somente a amostra de número 14 , coletada no ponto de atividade garimpeira mais antiga, apresentou concentração excessiva do metal, sendo qualificado como sedimento altamente poluí-

\section{REFERÊNCIAS BIBLIOGRÁFICAS}

1. BERLIN, M. Mercury. In: Fribel, L.; Nordberg, G.F.; Vouk, V. ed. Handbook on toxicology of metals. 2 ed. New York, Elsevier, 1986. p. 387-440.

2. CLARKSON, T. W. The pharmacology of mercury compounds. Ann. Rev. Pharmacol., 12: 375-406, 1972.

3. CONSELHO NACIONAL DO MEIO AMBIENTE. Resolução CONAMA n ${ }^{\circ} 20$ de 18 de junho de 1986; classifica segundo seus usos preponderantes as águas do Território Nacional em águas doces, salobras e salinas em 9 classes. Diário Oficial da República Federativa do Brasil, Brasília. Seção 1, pt. 2. 30 de julho de 1986.

4. CRAIG, P. J. Metal cycles and biological methylation. In: Hortzinger, O. ed. The handbook of environmental chemistry: the natural environment and the biogeo-chemical cycles. New York, Springer Verlag, 1986. v. 1A, p. 169-228.

5. DELFT, V. W. \& VOS, G. Comparison of digestion procedures for the determination of mercury in soils by coldvapour atomic absorption spectrometry. Anal. Chim. Acta., 209: 147-56, 1988.

6. LACERDA, L. D.; PAULA, F. F. F.; OVALE, A. R. C.; PFEIFFER, W. C.; MALM. O. Trace metals in fluvial sediments of the Madeira river Watershed, Amazon, Brazil. Sci. Total Environ., 97/98: 525-30, 1990.

7. LACERDA, L. D. \& PFEIFFER, W. C. Mercury from gold mining in the Amazon environment: an overview. Química Nova. S. Paulo, 15: 155-60, 1992. do por mercúrio, enquanto que as demais onde a atividade garimpeira teve início nos dois anos anteriores à coleta, os teores de mercúrio não caracterizam um sedimento contaminado ${ }^{12}$.

Os dados da Tabela 3 mostram que não há correlação entre os teores de mercúrio total presente na água, nos sólidos em suspensão e em sedimentos, coletados do mesmo local.

8. MAGOS, L. Mercury. In: Seiller, H. G.; Sigel, H.; Sigel, A. ed. Handbook on the toxicity of inorganic compounds. New York, Marcel Dekker, 1988. p. 387-437.

9. MILLER, J. C. \& MILLER, J. N. Statistics for analytical chemistry. 2 ed. Chicester, Ellis Horwood, 1988.

10. MINISTÉRIO DA SAÚDE. Portaria n ${ }^{\circ} 36$ de 19 de janeiro de 1990; aprova normas e o padrão de potabilidade de água destinada ao consumo humano a serem observadas em todo Território Nacional. Diário Oficial da República Federativa do Brasil, Seção 1, pt1. 30 de julho de 1986.

11. PFEIFFER, W. C.; LACERDA, L. D. MALM, O.; SOUZA, C. M. M.; SILVEIRA, E. G.; BASTOS, W. R. Mercury concentrations in inland waters of gold mining areas in Rondonia, Brazil. Sci. Total Environ., 87/88: 233-40, 1989.

12. PRATER, B. L. \& ANDERSON, M. A. A 96-hour bioassay of otter creek, Ohio. J. Water Pool. Control., 31: 2099-106, 1977.

13. TONG, S. L. Stationary cold-vapor atomic absorption spectrometric method for mercury determination. Anal. Chem., 50: 412-4, 1978.

14. WORLD HEALTH ORGANIZATION. Mercury. Geneva, 1978. (Who-Environmental Health Criteria, 1).

15. WORLD HEALTH ORGANIZATION. Mercury: environmental aspects. Geneva, 1989. (Who-Environmental Health Criteria, 86).

16. WORLD HEALTH ORGANIZATION. Inorganic mercury. Geneva, 1991. (Who-Environmental Health Criteria, 118). 